\title{
TURISMO E OS PARADOXOS NO CONSUMO E CONSERVAÇÃO DO AMBIENTE ${ }^{1}$
}

\author{
TOURISM AND THE PARADOXES IN THE CONSUMPTION AND \\ CONSERVATION OF THE ENVIRONEMENT
}

\section{TOURISME ET LES PARADOXES DANS LA CONSERVATION ET CONSUMMATION DE L`ENVIRONNEMENT}

\begin{abstract}
Maria Geralda de Almeida
Professora do Curso de Geografia do Instituto de Estudos Sócio-Ambientais (IESA) da Universidade Federal de Goiás - UFG. mgdealmeida @ gmail.com.
\end{abstract}

\section{Resumo}

A atividade turística é uma das formas de lazer, de uso do tempo livre de maior impulso nas ultimas décadas. Esta atividade, com raras exceções, quando praticada na natureza, tem se revelado como uma apropriação, uma modificação dos ecossistemas naturais.O turismo lança o seu olhar sobre a natureza fascinando-se por cenários e,também, os classificando. O olhar extasiado confunde-se com o olhar valorativo. Discute-se as contradições com a implementação do turismo, esse apropriando do ambiente, como um atrativo turístico e a crescente insistência de vinculá-lo ao dito “desenvolvimento sustentável”. Finaliza-se com uma discussão sobre as políticas de turismo visando maior consumo do espaço;

Palavras- chave: turismo, ambiente, sustentabilidade,impactos, políticas de turismo.

\section{Abstract}

\footnotetext{
${ }^{1}$-Texto apresentado no SBGFA, julho de 2007, na mesa- redonda “ Turismo e Meio Ambiente”.
} 
Tourist activity is a form of leisure activity practiced during an individual's free time, and has been expanding during the last decades. This activity, with rare exceptions, when practiced in the nature has appeared as an appropriation transforming natural ecosystems. Tourism markets nature, fascinating potential clients by classifying natural sceneries. The admirable view of nature thus is replaced by a capitalistic view. It is argued that tourism impacts the enviroment and is linked to the aspect of "soustenable development", concluding with a discussion on the politics of tourism seeking larger consumption of the space.

Words - key: tourism, enviroment, soustenable development, impacts, tourist politics.

\section{Resumé}

L`activité touristique est une manière d`emploi du temps libre et aussi de loisir assez developpé dans les dernières décades. Cette activité, quand il y a un rapport avec la nature, avec quelques exceptions, génère une modification des ecosystèmes. Le tourisme a un regard à la fois fasciné et valoratif des élements pour clasifié la nature. Dans cet article on met l`accent sur cette contradiction et d`autres, du tourisme á l’egard de la nature, et l’insistence croissante de l’attacher au nommé “développement soustentable”. Une discussion sur les politiques du tourisme envisageant une consummation accélerée de l’espace fait la clotûre des paradoxes de cette activité. Mots-clés: tourisme, environnement, soustentabilité, impacts, politiques du tourisme,.

\section{Introdução}

A globalização tornou-se, nas últimas décadas, a fase atual de forte expansão do capitalismo, consolidando o período denominado de meio cientifico-técnico informacional por Santos $(1994,1996)$ que gerou uma organização espacial completamente nova. Há uma fragmentação e especialização regional em escala internacional, cada lugar assumindo os processos de mudanças de maneira distinta de tal forma que os lugares globalizados tornam-se cada vez mais singulares.

Esta fase tem implicações na prática da atividade turística que neste contexto confronta-se não só com um tipo de modelo econômico dominante como também com 
os lugares, as regiões, e as sociedades regionais e locais determinando a diversidade de uso e da exploração turística, ou seja nas formas de fazer o turismo (Rodriguez, 2007).

A atividade turística, com raras exceções, quando praticada na natureza, tem se revelado como uma apropriação, uma modificação dos ecossistemas naturais. Os ecossistemas são um sistema de componentes bióticos e abióticos dos quais se formam os organismos, que estão estrutural e funcionalmente relacionados. A manutenção da vida nos ecossistemas depende da conservação das condições físico-químicas. Assim, quando a atividade do ser humano modifica as características de estrutura e composições da biosfera rompendo o equilíbrio das condições bio-físico- químicas, é todo o conjunto dos seres vivos que passa a ser ameaçada No caso do turismo a existência dessa atividade está relacionada com a existência ou criação da "paisagem turística”, para a implementação de infra-estruturas, de mega-projetos nos quais a natureza tornou-se a principal mercadoria. O ecoturismo, entendido em sua vertente patrimônio natural, motivado pela reinvenção da natureza tornada um recurso turístico, não escapa desta concepção capitalista e representa, também, uma forma de consumo da natureza.

E, se atualmente difunde o interesse pelo ambiente deve-se a ascensão do ambientalismo como uma poderosa arma ideológica. Esse fortalecimento coincide com a concepção de desenvolvimento sustentável como uma nova matriz discursiva, sendo um ponto de convergência no diálogo que abordava ambiente e desenvolvimento. A Conferência das Nações Unidas sobre Ambiente e Desenvolvimento-CUNAMAD, de 1992, foi o marco para intensos debates sobre a acelerada destruição do ambiente, o que compromete a reprodução da vida e do capital, e sobre proposições para a conservação do ambiente, isto é, das condições que assegurariam a manutenção dos processos de acumulação e para a adoção do desenvolvimento sustentável como paradigma atual.

Neste breve artigo o enfoque é para as relações entre o ambiente e o turismo. Tentarei _ adotando o proposto por Berque (1986), considerar o sentido que a sociedade dá à sua relação com o espaço e com à natureza e, nas modalidades das relações sociais, discutir o turismo enquanto produtor e consumidor do ambiente. Permeando essas questões com esse enfoque, há uma outra intenção: contribuir nas reflexões teórico- metodológicas, sobre o ambiente e o turismo.A pretensão é de 
manter aceso o debate, tendo clareza que esta síntese retoma elementos já discutidos por estudiosos desta temática.

\section{1 -As múltiplas interpretações de ambiente}

É vertiginosa a ascensão da noção de ambiente. Ela aparece, no século XX, como uma grande revolução na forma de pensar o mundo e, mais particularmente, as relações do homem com a natureza.

Todavia, tanto o termo como o seu uso são uma fonte abundante de confusões e digressões. Seus diversos sentidos permitem que todos falem sobre o ambiente e, compreendem-no, entretanto, cada um à sua maneira.

Sua evolução semântica mostra que, inicialmente, foi entendido como uma referência ao não-vivo (clima, rocha, água); em seguida ampliou-se, para incluir as formações vegetais, depois as biocenoses, adotando uma concepção mais naturalista, de forte conotação biológica o "ambiente natural". Só mais recentemente o termo "ambiente" infiltra o domínio social, o econômico e o cultural; primeiramente, com implicações biológicas e, posteriormente, com referência à noosfera. Essas, segundo Theilhard de Chardin considera que a Terra, no seu infinito poder criativo, concebeu o ser humano a quem entregou a responsabilidade de gestar o futuro da vida no planeta. Ela está, pois, constituída pelo manto de idéias que cobre a Terra ( apud Negret, 1994)

Cabe lembrar que, o conceito básico de ambiente foi originalmente elaborado pela ecologia vegetal, no final do século XIX. Essa definiu o "meio" ( natural ) como o conjunto de condições externas e outras influências que afetam o crescimento e o ciclo de vida dos organismos vivos. Com a introdução do conceito de ecossistema, fins dos anos 1930, o meio natural é, cada vez mais , apreendido e concebido como o ambiente das sociedades, pouco transformado ou não intensamente utilizado e degradado. Pouco a pouco o ambiente ganha um corpo teórico transdisciplinar, talvez mais naturalista do que social; porém, por parte de algumas correntes, e mais recentemente, o ambiente é interpretado com uma visão mais holística das relações natureza/sociedade.

No caso da Europa, no início dos anos setenta, uma assimilação entre ambiente e meio geográfico confere tanto um como o outro uma conotação naturalista. Exemplificando com a França, a partir de 1975 uma releitura é feita procurando situar o ambiente no contexto social; nos anos seguintes, diante do caráter global das relações 
natureza-sociedade, a abordagem geográfica evolui-se para a análise sistêmica. Já na década atual, novos temas surgem no seio das preocupações ambientais como poluição, catástrofes e riscos, gestão de recursos naturais, recursos naturais e geografia política, sustentabilidade, acompanhados do enriquecimento das abordagens metodológicas e teóricas .

Alguns autores ( Pinchemel,1988; Gonçalves,1989 e Becker,1992) nos falam de ambiente como um sistema no qual interagem, simultaneamente ou não, num mesmo espaço ou não, três esferas de componentes naturais e sociais: "ambiente natural" no qual as estruturas abióticas e bióticas funcionariam independentes dos perceptíveis que se estabelecem, de um lado entre ambiente natural e grupos sociais e, de outro, nos próprios grupos sociais. Os problemas sociais seriam assim uma perturbação decorrente da inter-relação das três esferas ambientais.componentes sociais, o "ambiente construído", em que se verifica a situação contrária e um "ambiente social", que resulta da complexa rede de relações/valores não visíveis e indiretamente perceptíveis que se estabelece, de um lado entre ambiente natural e grupos sociais e, de outro, nos próprios grupos sociais. Os problemas sociais seriam, assim, uma perturbação decorrente da inter-relação das três esferas ambientais.

Esta concepção do ambiente no qual domina a presença do homem é também defendida por Rodriguez (2007, p.86), para quem o ambiente deve ser entendido como "um ecossistema humano formado pela interconexão entre o sistema humano com os sistemas ambientais que compõem seu meio ambiente ( ou seja, o sistema natural e os sistemas sócio-econômico-cultural”)

Permeando aquele ou este entendimento, as interpretações dadas ao ambiente reforçam os mesmos aspectos. Cito, para reforçar e sintetizar estas concepções sobre ambiente, aquela proposta por J.J. Melo e C. Pimenta ( apud Delvy-Vareta, 1995, p. 21 ) definindo-o como " conjunto de sistemas físicos, ecológicos, econômicos e sócioculturais com efeito direto ou indireto sobre a qualidade de vida do homem".

Entendido desta forma, a problemática do ambiente envolve todas as ciências, particularmente as do campo social. Atualmente, nos cenários global e local como nos cenários presentes e futuros, discursos associam o ambiente com o desenvolvimento. Há uma ênfase em que o "verdadeiro" desenvolvimento é aquele compatível com a qualidade ambiental e com uma utilização sustentada dos recursos. Este entendimento de ambiente iniciou-se durante a Conferência das Nações Unidas sobre Ambiente e 
Desenvolvimento, em 1972, em Estocolmo. Esta idéia fortaleceu-se na CUNAMAD Rio-92 quando ambiente e desenvolvimento passaram a ser efetivamente considerados como dimensões norteadoras do progresso econômico e social, conforme já foi mencionado na introdução deste artigo. As questões ambientais constituem, sem dúvida, um campo de enfoques e discussões transversais, sobretudo quando referem-se também ao turismo.

\section{2- O ambiente e a invenção da atração turística}

Para o turismo, o ambiente resultaria de uma combinação entre o natural e o cultural sendo que é a cultura que atribui significado ao outro." O ambiente é pois um território, isto é, uma mescla de natural e de artificial, uma humanização da natureza e uma naturalização do homem," no entender de Besse (1992, p.18), e o seu horizonte só tem sentido no contexto das representações humanas.

A cultura de cada sociedade contém, no seu bojo, a compreensão e leitura da natureza. Sendo assim, a cultura entendida como "o que tem sentido no mundo e dá sentido ao mundo", nas belas palavras de Berque (1986), ela é o agente mas, também, qualifica o objeto turístico. Ela participa de sua invenção. O objeto turístico, assim como o valor cultural, não é imanente, não surge a partir desses mesmos objetos, práticas e idéias. Aquilo que chamamos de bens culturais não têm em si sua própria identidade, mas a identidade que os grupos sociais lhe impõem. O objeto turístico, portanto, em si não existe, sendo uma invenção para e pelo turismo, responsável pela sua invenção. Assim também são os espaços, os lugares e territórios turísticos que, se nós quisermos discutir sua rápida expansão pelo território brasileiro deverá ser à luz de que, “planejados, construídos pelos empreendimentos turísticos ou mesmo decretados, institucionalizados, eles consistem pois, no estabelecimento de nova estrutura sócioespacial, cujo eixo de compreensão terá de emergir não da leitura do turismo, mas das relações da sociedade com o lugar e mais ainda, dos homens entre si, na sociedade” ( Almeida, 1998 p.19).

Porém, conforme Dewailly (1993), o lugar só adquire valor turístico quando ele responde a uma demanda existente ou latente, quando ele se confunde com as aspirações, os gostos e mitos de uma época. Enfim, o desejo de desterritorializar-se suscitado pela imagem que o turismo cria, a propaganda que lhe dá corpo, faz com que 
o homem procure cada vez mais a fantasia, o exotismo, a nostalgia, o novo, o diferente, sendo a natureza o que mais se presta a atender os apelos do imaginário do homem citadino, por excelência, o turista. Não se pode esquecer que a prática turística é uma necessidade das sociedades dos países industrializados, porém, realizada, principalmente, pelas camadas economicamente favorecidas de todos países.

Vários são os estímulos: os recursos naturais como vegetação fora do comum, vida selvagem para ser observada e fotografada, áreas marítimas de arrecifes para observações e para prática de mergulho, cavernas, montanhas, cachoeiras e cursos d'água...enfim, há uma progressiva apropriação dos diversos ecossistemas naturais pelo uso turístico.

O turismo lança o seu olhar sobre a natureza e, ao mesmo tempo em que se fascina por cenários no qual a mercadoria e valor de uso não são as preocupações essenciais das sociedades tradicionais, ele a classifica, a aprecia pela sua identidade passível de ser marketing turístico e promovida mundialmente. O olhar extasiado confunde-se com o olhar valorativo. As atrações naturais, pelas paisagens e imagens, bem como as atrações derivadas de herança cultural como locais arqueológicos, históricos e religiosos, edifícios com uma arquitetura particular, museus, etnias, estilo de vida, festivais culturais, artesanato tradicional e contemporâneo dão reputação ao lugar criando o turismo paisagístico.São essas atrações que influenciam o imaginário e determinam a escolha das destinações pelos turistas.

A sociedade contemporânea, com o turismo, revaloriza uma natureza que, muitas das vezes já foi dessacralizada, objetivada e manipulada exaustivamente. Segundo Serrano (1997), na atualidade é com base na representação da natureza como paisagem, e como cenário para as ações humanas, que se institui o seu consumo pelo turismo. O turismo tem como uma sua característica o consumo visual, reforçada pela produção concreta de seus lugares turísticos, isto é, o ambiente construído, ou território, bem como pela representação da natureza como cenário, conforme já foi dito. Numa época em que as mudanças para uma economia do consumo e do lazer se fortalecem, o turismo ecológico, o turismo verde ou ecoturismo ou turismo natural tornam-se os segmentos mais promissores de uma das atividades mais dinâmicas da economia mundial.

No caso do Brasil, em 2005, o país recebeu 5,25 milhões de turistas. Entre os principais visitantes 18,9\% vieram da Argentina, 14,8 dos Estados Unidos e 4,7\% de 
Portugal.(Embratur 2006). Sem dúvida ganham notoriedade suas praias, seus vastos espaços naturais, seu exotismo cultural, em suma, sua diversidade paisagística e riqueza ambiental ampliando os fluxos turísticos para o território brasileiro. Nesta imagem que está sendo construída tem um papel importante a ação do Estado que considera o turismo como uma das estratégias para o desenvolvimento regional e local.

Existe uma forte demanda para o desenvolvimento do ecoturismo nacional, sobretudo visando os distintos ecossistemas e uma expressiva biodiversidade que atraem principalmente os turistas internacionais.Presentemente, o mercado de turismo receptivo centra-se nos grandes destinos ecológicos como a Amazônia, - com seus eco-hotéis, também conhecidos como “hotéis de selva” ou lodges - o Pantanal, algumas regiões da Mata Atlântica e Foz de Iguaçu.

Estes projetos hoteleiros são, em sua maioria, de grandes grupos estrangeiros. De acordo com a Revista "Exame” de 07/03/2001 as principais cadeias hoteleiras internacionais - Sofitel, Holiday Inn, Caesar Park, Sol-Meliá, entre outras - e grupos empresariais nacionais previam inversões, nos próximos cinco anos, na ordem de 8 bilhões de dólares na construção de resorts, spas, hotéis, parques temáticos, campos de golfe, em todo país,criando lugares e regiões turísticas e reconfigurando, assim, uma nova regionalização do espaço brasileiro..

Tornou-se claro, a partir dos fins da década de oitenta, do século XX, que não é possível equacionar as questões de ambiente descontextualizadas do econômico e vice versa. Este é um dos momentos mais propícios para manter o crescimento do turismo, pelos capitalistas, alegando ser esta considerada como uma "indústria sem chaminé", limpa por excelência.Além da comparação com indústria ser equivocada, posto o turismo ser uma atividade do setor de serviços, esse é um discurso sintonizado com o novo valor que tanto a natureza quanto a cultura têm para a economia neoliberal (Ribeiro; Barros, 1997). Outros discursos aos poucos surgiram e suplantaram esse do turismo como indústria, passando atualmente a prevalecer um entendimento que a ênfase não deveria ser tanto para sua classificação nos setores econômicos, e sim, para a sua compreensão como uma atividade geradora de emprego e renda apoiando-se mormente na existência e exploração de recursos naturais.

\section{Ecoturismo e as controvérsias do desenvolvimento sustentável}


Entre as atividades turísticas o ecoturismo é o segmento que apresenta maiores taxas de crescimento, sendo o mais estimulado para as regiões ricas em ambientes naturais e, paradoxalmente, pobres em economia. É o caso do Brasil.

Segundo a Embratur o ecoturismo é "um segmento da atividade turística que utiliza, de forma sustentável o patrimônio natural e cultural, incentiva sua conservação e busca a formação de uma consciência ambientalista pela interpretação do ambiente,promovendo o bem estar das populações" (BRASIL, 1994, p.19).

Convém esmiuçar um pouco esta definição para entendermos esta modalidade de turismo. Em um primeiro momento é evidente que a mesma está formulada em sintonia com o discurso do desenvolvimento sustentável. Este tem uma concepção embasada na compatibilização entre crescimento econômico e preservação ambiental; também, ele enfatiza a necessidade de garantir o patrimônio ecológico para gerações presentes e futuras. Ora, uma crítica que aflora imediatamente com a sua leitura é que, considerando o elitismo que permeia a concepção e a prática do ecoturismo, é questionável quais as populações que teriam asseguradas o uso do patrimônio ecológico de imediato e futuramente.

De acordo com Beker (apud Davidovich,1993), a proposta de desenvolvimento sustentável objetiva uma regulamentação globalizada do desenvolvimento definindo papéis e diretrizes específicas para países periféricos. As conotações políticas e estratégicas dessa tese são numerosas significando em maior controle do crescimento econômico de países economicamente dependentes. O desenvolvimento sustentável seria, portanto, um "instrumento político de regulação do uso do território" atendendo os interesses determinados pelos paises economicamente poderosos. Ele revela-se, também, contraditório: ao mesmo tempo em que acena para o crescimento econômico de países periféricos, propõe sua subordinação à primazia da conservação do meio ambiente. Este paradoxo tem sua razão por se respaldar na defesa de um liberalismo total da economia.

Para diversos autores, críticos da economia liberal, o desenvolvimento sustentável representaria uma estratégia para a consolidação de uma composição política que envolve hegemonia universal e soberanias limitadas. Assim, apesar da aparente neutralidade e da tentativa de apontar sua preocupação com a educação ambiental, este estilo de desenvolvimento não consegue ocultar completamente o sentido de mercantilização da natureza, típico da atividade turística. E mais: o recurso à 
sustentabilidade possibilita que o turismo, como uma prática econômica , apresente-se como tendo um fim em si mesmo: exploração "não destrutiva da natureza" para gerar recursos para "conservar a natureza"/"atrativos conservados"/"proteger a natureza". De acordo com Silva (1997, p.146), tal circularidade impede questionamentos que pudessem reverter o sentido histórico dessa e das outras práticas econômicas da sociedade.

Mais recentemente, Rodriguez (2007) demonstrou o peso das correntes políticoideológicas para estabelecer uma interessante tipologia do paradigma da sustentabilidade turística no qual prevaleceriam as seguintes visões:

- a dos neoliberais, que entendem o turismo como uma esfera fundamentalmente econômica, competitiva, de mercado livre e aberto;

- os capitalistas reformistas, que propõem a melhoria da qualidade ambiental dos espaços turísticos com alterações do comportamento humano e a introdução de tecnologias;

- os eco socialistas, para os quais há necessidade de um processo de mudanças sociais profundas, que altere radicalmente as estruturas econômicas e políticas. Neste processo compete ao Estado definir e administrar a exploração turística, aglutinar os esforços dos diversos grupos sociais e redistribuir para toda sociedade os produtos e benefícios dessa exploração;

- os partidários de um desenvolvimento local, defensores da adoção de formas de exploração turística ajustadas às características ambientais locais, respeitando a escolha e definição do tipo de turismo escolhido pelas comunidades.

No Brasil existe muita discussão sobre a atividade turística nas esferas das políticas, do ambiente e da sociedade devido aos interesses diversos e divergentes, conforme essas quatro interpretações dadas.Mais que o bom senso tem prevalecido o jogo do poder político e econômico, porém, cresce uma consciência e prática de um turismo centrado no desenvolvimento local, assunto a ser posteriormente abordado.

Esses debates devem-se ao crescimento da demanda por atividade ecoturística. Todavia, aproveitando-se deste rótulo, observa-se uma vulgarização do termo aplicado para vender pacotes de passeios, excursões ou visitas para qualquer ambiente natural. Ecoturismo tornou-se sinônimo de natureza. De fato, a forte percepção mundial acerca da necessidade urgente de proteção e recuperação dos recursos naturais, originária, principalmente, da disseminação dos movimentos conservacionistas empreendidas por 
grupos ambientalistas, forças políticas e marketing, acabam por influenciar nos roteiros e destinos dos " ecoturistas" . Nega, entretanto, uma outra vertente do ecoturismo, ou seja, a valorização do patrimônio cultural e das sociedades tradicionais portadoras de conhecimentos sobre estes ambientes considerados naturais. Para além dos " passeios" é o contato com as comunidades locais que constitui o caminho rico para a experiência e a interpretação do ambiente e uma verdadeira educação ambiental .

\section{O ambiente turistificado, problemas e vias de soluções}

O estresse da vida moderna e a efervescência da vida nas cidades favorecem a busca cada vez maior do contato com a natureza, sobretudo em área minimamente alterada ou em áreas protegidas. Os visitantes da natureza têm a crença que esta repõe as energias gastas e cria novo alento para enfrentar o ritmo urbano.

Baseando-se nesta crença, a prática turística é estimulada em unidades de conservação e várias vantagens são alegadas por seus defensores: a adesão de visitantes às tarefas de fiscalização; o aumento da oferta regional de espaços de lazer e recreação; a possibilidade de uma maior integração das áreas protegidas com comunidades locais e com a sociedade de maneira mais ampla; divulgação ambiental via programas educativos e da própria visitação e, o estabelecimento de "redes" de interessados em sua manutenção (Boo,1992). Positivamente aponta-se, ainda, em unidades de conservação como parques nacionais e RPPN’s um crescimento de medidas de proteção incentivadas pela presença de condutores, moradores do entorno dos parques e proprietários das reservas.

Entretanto, numerosos são os estudos que apontam para os problemas decorrentes da turistificação, isto é, do processo de implementação desta atividade nos diversos ambientes. Os espaços naturais de "rara beleza cênica" transformam-se em ambiente social, ou melhor, em territórios turísticos pela implantação de equipamentos turísticos; determinados espaços naturais deterioram-se ou reduzem-se. As paisagens banalizam-se e perdem o encanto e a possibilidade de evocarem a aventura e fantasia. Além disso, as edificações podem levar a processos erosivos de difícil contenção, tornando a degradação do solo e sua exposição às intempéries cada vez maior. 
O turismo contribui também para o processo de especulação imobiliária que secundariza as características ambientais levando a ocupação de dunas, manguezais, falésias e florestas e a privatização de praias.

Há, também, um empobrecimento gradativo, de valores, da cidadania e do financeiro quando as atividades tradicionais de agricultura, pesca e de extrativismo são trocadas/substituídas por outras atreladas a um turismo sazonal. A desconsideração dos elementos culturais locais no desenvolvimento de atividades turísticas está relacionada, igualmente, à degradação ambiental

No caso da instalação de equipamentos turísticos a população local muitas vezes é desenraizada do seu local de moradia e de sua atividade de trabalho. A perda da terra e do trabalho desterritorializa a mesma e fragiliza seus valores locais.Além disso, o impacto da prática turística reflete nos indicadores do estado ambiental tais como a qualidade visual, a contaminação,critérios de infra-estrutura ambiental como saneamento, coleta e destino de lixo, abastecimento de água.

No que diz respeito ao turismo em áreas protegidas, autores apontam os seguintes impactos: necessidade de "sacrifício" de áreas para descanso e para aberturas de trilhas e acessos; construção de infra-estrutura etc.; na compactação, na erosão e na abertura de atalhos em trilhas; na depredação da infra-estrutura, das rochas e das árvores por pichações ou na coleta de souvenirs; no distúrbio do ambiente sonoro, visual e olfativo da fauna, por barulho, excesso de cores e odores estranhos ao meio..

Com o turismo, o olhar apreciativo e valorativo de um forasteiro é suficiente para criar um novo valor o que pode ocorrer no Brasil e na Europa. Foi o caso, por exemplo, do local de Beach Park, no Ceará. Maior complexo de lazer aquático instalado no litoral cearense, na Praia das Dunas, era, até o inicio dos anos 1990, um vasto campo de dunas. O espaço teve suas potencialidades geográficas e de localização adaptadas às finalidades turísticas que se espera dele, conforme Almeida (1998). Atualmente conta com um tobo-água cuja altura corresponde a um edifício de 14 andares e, apresentado em seu site como “o maior neste gênero no mundo", piscinas com ondas, um rio artificial, 17 brinquedos, 2 restaurantes, lanchonetes, lojas e uma praia semi-privada. A chegada da Euro Disney a Marne-la-Vallée, na França, deu-se com a ocupação de antigos campos de beterrabas e de cereais. Com o turismo atraindo, em 10 anos, cerca de 110 milhões de visitantes, substituiu-se o valor agrícola por um novo e maior (Équipe MIT, 2002). A cidade de Pirenópolis - Goiás, construída no século XVIII, com 
a mineração do ouro, cresceu e prosperou durante o curto período no qual esta atividade foi importante, passando por uma fase de declínio quando outras atividades econômicas desenvolveram-se e dinamizaram as demais regiões goianas. A partir de 1990, com o asfalto indo até Brasília, Pirenópolis reinventa-se pela festa das Cavalhadas, que rapidamente ganha destaque e se integra ao calendário nacional de festas do país, atraindo centenas de visitantes durante os festejos.

Diante deste quadro contraditório de vantagens e desvantagens para a dinâmica ambiental, o turismo surge pois, como o produtor dos lugares turísticos relacionados com a natureza e a cultura; e emerge como aquele que cria, contraditoriamente, a sua própria destruição.Coloca-se, portanto, uma questão essencial: é possível turistificar-se sem destruir as especificidades ambientais consideradas como bens turísticos?

Casos de ocorrência de uma valorização de maior participação por parte de comunidades e populações locais na definição da aceitação do tipo de turismo e no planejamento do turismo desejável são registrados como experiências bem sucedidas. Também é lembrada a valorização dos procedimentos de parceria entre atores públicos, privados e associativos na busca de estratégias que conciliem conservação e turismo.

Um elemento fundamental de uma política de turismo e gestão ambiental eficaz e socialmente aceita é assim o conceito de "responsabilidade compartilhada", surgido na junção da visão dos eco socialistas e da visao dos adeptos da participação efetiva das comunidades na definição e escolha do modelo de turismo por elas adotado. Essa consiste em trocar uma visão de um trato das questões ambientais, em que de um lado existem os agentes infratores e do outro lado o Estado fiscalizador-punidor, por uma outra na qual há uma responsabilidade e ação assumidos por todos os agentes sociais. Estes, governamentais e não-governamentais, desempenham as tarefas articuladas e complementares que permitem alcançar objetivos ambientais em torno dos quais é estabelecido um consenso social. Diálogo e senso comum, bem como a transparência da tomada de decisão são condições necessárias para uma efetiva co-responsabilidade.

Cabe aos formuladores de políticas ambientais com o auxílio da sociedade civil desembaraçar-se do conceito de "desenvolvimento sustentável", conceito vago e ambíguo e de duvidosa operacionalidade prática mas, sem dúvida politicamente apelativo. Freqüentemente o desenvolvimento sustentável é utilizado para justificar as mais variadas e contraditórias decisões perante os problemas de desenvolvimento. 
Todavia, suas conseqüências sobre a qualidade do ambiente e o equilíbrio do suporte ecológico, ainda carecem de mais estudos e merecem pois, restrições na sua aplicação.

\section{Para finalizar: ambiente e turismo nas tramas das políticas...}

Ao encerrar esta discussão merece um esclarecimento no que concerne ao fato de a existência de elementos naturais como quedas d' água, montanhas, vales, mar, neve, águas com qualidades especiais, vegetação, grutas e cavernas, lagos, canyons, serem freqüentemente mencionados como criadores de lugares turísticos.Todavia, observando cartas e mapas com a distribuição destes elementos da natureza, ou destes recursos, nota-se que há neles uma predominância de vazios de lugares turísticos. Ou seja, a existência da natureza não é suficiente para criar o lugar turístico.Também, há que se considerar que, basear o desenvolvimento turístico sobre "elementos naturais” é, ainda, apoiar-se sobre uma dicotomia entre o homem e a natureza e sobre uma visão racional discutível.

Em outras palavras, nem todos elementos naturais, também são convertidos em recursos, isto é, “recurso só existe em função de uma prática, de um indivíduo capaz de mobilizar um saber”, nas palavras de Raffestin (1993, p. 225). Ilustra-se com o caso das dunas do Parque Nacional dos Lençóis Maranhenses. Para a população local, as dunas são áreas de areia em movimento e importantes pela absorção de água das chuvas e formação de lagoas. Para os moradores, malgrado o reconhecimento da beleza da vastidão dos campos dunares, causa surpresa o fluxo de visitantes para visitar o Parque. A partir do instante em que houve localmente geração de emprego e renda, com a movimentação de turistas, os Lençóis Maranhenses tornaram-se recurso social para a população, e o Estado intensificou as políticas de valorização, associado à iniciativa privada na exploração do Parque Nacional.

O turismo é híbrido sendo simultaneamente um enorme potencial de desenvolvimento econômico e, igualmente, de degradação do ambiente. Híbrido, também, no sentido de ser o turismo um produtor e consumidor de ambiente quando o Estado, investidores privados e comunidades incentivam a sua prática..

Entretanto, no contexto atual de valorização dos aspectos econômicos do turismo os planejadores e empreendedores têm negligenciado os estudos e a consideração dos aspectos relacionados com a natureza, a cultura e os aspectos 
psicossociais dos locais receptores. Alguns equipamentos turísticos chegam mesmo a serem instalados sem a observância do EIA/RIMA. Ora, se um investimento é decidido em função da paisagem de um ecossistema determinado, o que acontece quando esse começa a degradar-se, a corromper-se por motivos biológicos ou pela ação do homem depredador?

Um estudo ambiental como condição prévia para a instalação do empreendimento turístico auxiliaria na definição da compatibilidade entre o ecossistema e a atividade a ser desenvolvida e vice-versa. Esse estudo alimentaria as previsões referentes ao uso dos recursos naturais sinalizando os custos pelo consumo desses em função das atividades introduzidas. Sem dúvida ele, também, facilitaria aos planejadores e investidores adiantar-se à deterioração e a combatê-la.

A despeito de uma política nacional do turismo, lançada em 1992 e a instituição do Plano Nacional de Turismo, também no mesmo ano, descentralizando, diversificando e distribuindo geograficamente a infra-estrutura turística, de fato, apenas o Nordeste, com o Programa de Ação para o Desenvolvimento do Turismo no Nordeste Brasileiro, vingou-se. A política federal, também instituiu o Plano Nacional de Municipalização do Turismo, em 1992, delegando uma maior autonomia aos estados e municípios. Na prática isto contribuiu para uma maior concorrência por recursos e investimentos entre estados e municípios impedindo parcerias e a responsabilidade compartilhada. $\mathrm{O}$ atual governo federal decidiu por uma outra estratégia, abandonando o Plano da Municipalização e lançou o Plano de Regionalização de Turismo, em substituição a àquele para o período 2003-2007.O Ministério do Turismo ufana-se da criação de 396 roteiros turísticos abrangendo 1.027 municípios e 149 regiões turísticas. Já como parte da implementação do Programa de Regionalização, ele reafirma a sua intenção de efetuar a estruturação de roteiros integrados entre os municípios. Os geógrafos pouco têm comentado sobre este plano, baseado em uma categoria geográfica, e perdem uma boa oportunidade para com seus conhecimentos contribuírem efetivamente com a sociedade e com o Estado no que diz respeito às políticas sócioespaciais.

Um conflito de concepção manifesta-se, também, nas políticas setoriais: no caso do litoral, a política de turismo é eminentemente desenvolvimentista enquanto a política do Ministério do Meio Ambiente para essa região é nitidamente ambientalista; ora, a ação do homem é rápida, ela perturba o comportamento da natureza, todavia, as 
respostas desta, adaptando-se às novas situações criadas pelo comportamento humano, são lentas. O tempo tem um duplo referencial: um tempo curto para a ação humana e um tempo longo para o comportamento e reação da natureza. Em outras palavras, turismo e ambiente estão em descompasso temporal.

Também, tem que se considerar que os planos, os projetos de regeneração de ambiente somente dão resultados após um longo lapso de tempo: os mandatos dos políticos são bem mais curtos. Mesmo tendo prorrogações não representam nada, confrontados ao tempo de ajuste e de regeneração da natureza face à uma agressão ou à uma prática destruidora.

\section{Referência bibliográfica}

ALMEIDA,M.G. 2005. A produção do ser e do lugar turístico.In SILVA, J.B.; LIMA, L.C; ELIAS,D. (orgs). Panorama da Geografia brasileira.Sao Paulo:Annablume,pp.109122.

ALMEIDA, M. G. 2003. Lugares Turísticos e a falácia do intercâmbio cultural. In: ALMEIDA, M.G. Paradigmas do Turismo.Goiânia: Alternativa, pp. 11-22.

ALMEIDA, M.G. 1998. Cultura - invenção e construção do objeto turístico. Espaço Aberto 3, Turismo e formação profissional. Fortaleza: AGB/FUNCAP.

BECKER, B. 1996. Políticas e planejamento do turismo no Brasil, In YAZIGI E. et. al Turismo: espaço, paisagem e cultura. São Paulo: Editora Hucitec.

BERQUE, A. 1986. Le sauvage et l'artifice Les Japonais devant la nature, Paris:Gallimard.

BESSE, J-M. 1992. Le point de vue du philosophe. In A.F.D.G. Spécial géoforumGéographes Associés. GAN ${ }^{\circ}$ 10, Université de Bourgonge/ CNRS, 1er semestre de 1992.

BOO, E. 1992. Ecoturismo:potencialidades e vias.(mimeo) .

BRASIL 1994. Diretrizes para uma política nacional de ecoturismo. Sílvio Magalhães Barros II, Denise Hamú M.de La Penha (coord.).Brasília: Embratur.

DAVIDOVICH,F. 1993. A propósito da Eco-Urb's 92: a temática Urbana na Questão Ambiental. In: MESQUITA,O.O, TIETZAMANN T,S (coord)Geografia e a questão ambiental.Rio de Janeiro: IBGE, Departamento de Geografia.

DELVY-VARETA, N.D. 1995. Geografia, vegetação e problemática ambiente.Inforgeo. Ambiente e Território. 9 \& 10. Lisboa. Associação Portuguesa de Geógrafos.

ÉQUIPE MIT. 2002. Tourisme 1. Lieux communs. Paris : Belin. 
FARIA, D. S\& CARNEIRO, K.S. 2001. Sustentabilidade ecológica e Turismo. Brasilia: Editora UnB.

MARINHO,A. BRUNHS, H.T.(orgs). 2003. Turismo, Lazer e Cultura. São Paulo: Manole.

MINISTERIO DO TURISMO. Roteiros do Brasil. Programa de Regionalização do turismo. Produtos Turisticos. Escolha o seu roteiro e boa viagem. Produtos Turisticos Brasília:Ministério do Turismo, s/d. - Plano Nacional do Turismo. Diretrizes, Metas e Programas.2003-2007.

MOLINA, S. 2001. Turismo e Ecologia. Bauru,SP:EDUSC.

NEGRET, R. 1994. Na trilha do desenvolvimento sustentável -ecologia natureza sociedade. Alto Paraiso:ITDS

RAFFESTIN, C. 1993. Por uma geografia do poder. São Paulo: Ática.

RUSCHMANN,D.V.M. 1997. Turismo e planejamento sustentável: a proteção do meio ambiente. Campinas: Papirus.

RIBEIRO,G.L.BARROS,F.L. 1997.A corrida por paisagem autênticas: turismo, meio ambiente e subjetividade no mundo contemporâneo In:SERRANO,C.M.,BRUHNS, H,T (orgs) Viagens à natureza: turismo, cultura e ambiente. Campinas:Papirus.

RODRIGUEZ, J.M. M.2007. Turismo y desarrollo sostenible en América Latina. In: SEABRA, G.(org.) Turismo de base local: identidade cultural e desenvolvimento regional.João Pessoa:Editora Universitária/ UFPB.

SEBRAE. 2002. Turismo Ecológico. $4^{\mathrm{a}}$ edição.Porto ALegre:Ed.SEBRAE.Série Desenvolvendo o Turismo. vol.2

SERRANO,C.M. 1997. A vida e os parques: proteção ambiental, turismo econflitos de legitimidade em unidades de conservação.In SERRANO,C.M.BRUHNS,T. (org.)Viagens ä Natureza: Turismo, cultura e ambiente. Campinas: Papirus.

sites:

www.beachpark.com.br.( consultado dia 22/12/2005)

www.caldas.com.br.( consultado dia 26/12/2005)

www.morrodesaopaulo.com.br (consultado dia 05/01/2006)

www.parquelencois.com.br/artigos/index.php. ( consultado dia 07/01//2006)

http://www.trancosobahia.com.br/ (consultado dia 05/01/2006)

Recebido para publicação em novembro de 2007

Aprovado para publicação em dezembro de 2007 